\title{
Minimal Access vs. Open Spine Surgery in Patients With Metastatic Spinal Cord Compression - A One-Center Randomized Controlled Trial
}

\author{
SØREN SCHMIDT MORGEN ${ }^{1}$, LARS VALENTIN HANSEN ${ }^{1}$, TURE KARBO ${ }^{1}$, \\ ROBERT SVARDAL-STELMER ${ }^{1}$, MARTIN GEHRCHEN ${ }^{1}$ and BENNY DAHL ${ }^{1,2}$ \\ ${ }^{1}$ Spine Unit, Department of Orthopedic Surgery, Rigshospitalet, \\ Copenhagen University Hospital, Copenhagen, Denmark; \\ ${ }^{2}$ Division of Orthopedic Surgery, Texas Children's Hospital and Baylor College of Medicine, Houston, TX, U.S.A.
}

\begin{abstract}
Background/Aim: We conducted a randomized controlled trial to investigate whether minimally access spine surgery (MASS) is less morbid than open surgery (OS) in patients with metastatic spinal cord compression (MSCC). Patients and Methods: A total of 49 MSCC patients were included in the trial. The outcome measures were bleeding $(L)$, operation time (min), re-operations and prolonged wound healing. Results: The median age was 67 years (range $=42-85$ years) and $40 \%$ were men. The peri-operative blood loss in the MASS-group was significantly lower than that in the OS-group; $0.175 \mathrm{~L} v$ s. $0.500 \mathrm{~L},(p=0.002)$. The median operation time for MASS was $142 \mathrm{~min}$ (range $=72-203 \mathrm{~min}$ ) vs. 103 (range $=59$ $435 \mathrm{~min})$ for $\mathrm{OS}(p=0.001)$. There was no significant difference between the two groups concerning revision surgery or delayed wound healing. Conclusion: The MASS technique in MSCC patients is associated with less blood loss, but a longer operation time when compared to the OS technique.
\end{abstract}

In recent years, an increasing number of cancer patients develop symptomatic metastatic spinal cord compression (MSCC). This is most likely a result of the advancement in cancer treatment and prolonged survival among cancer patients in general $(1,2)$. The optimal treatment for MSCC patients is considered to be surgery in combination with radiation therapy $(3,4)$. However,

This article is freely accessible online.

Correspondence to: Søren Schmidt Morgen, MD, Ph.D., Spine Unit, Department of Orthopedic Surgery, Rigshospitalet, Copenhagen University Hospital, Copenhagen, Denmark. Tel: +45 35456805, Fax: +45 35452165, e-mail: s@smorgen.dk

Key Words: Metastatic spinal cord compression, spinal surgery, spinal metastases, vertebral metastases, operation time, bleeding, minimal access surgery. the majority of patients are not recommended surgical treatment due to poor health and relatively short survival time, which means that they cannot withstand large surgical procedures (5, 6). Minimally access spine surgery (MASS) is considered less morbid than open surgery (OS), and results in fewer wound complications and less bleeding. The existing evidence for bleeding in minimal versus open surgery from observational studies is gathered in two recently published reviews by Pennington and colleagues and by $\mathrm{Lu}$ and colleagues. The conclusions were that "The overall quality of evidence currently available is low-all evidence is currently class III or IV" $(7,8)$. With this clinical trial we aimed to examine the perioperative bleeding, surgery time and number of revisions of MASS compared with conventional OS in the treatment of patients with MSCC. The hypothesis of the study was that MASS results in significantly less blood loss, shorter surgery time and fewer revisions when compared to open surgery.

\section{Patients and Methods}

Study population. The study includes MSCC patients admitted to Rigshospitalet, Denmark from January 1 1t, 2014 to January $1^{\text {st }}, 2017$. The hospital serves a population of 2.3 million people from the eastern part of Denmark. The MSCC diagnosis was based on magnetic resonance imaging (MRI) in combination with clinical symptoms such as back pain and/or neurological impairment. Patients with MSCC between T5 to L3 where included. Patients with Tokuhashi score $\leq 4$, in need of sacral or iliosacral instrumentation, and patients who were candidates for a corpectomy were excluded.

All patients were included in the study at referral and information regarding age, sex, primary oncological diagnosis was registered. According to the hospital guidelines, the on-call oncologist examined all patients and the treatment strategy was decided within $24 \mathrm{~h}$ after admission.

Study design. This study is a non-blinded, randomized controlled, parallel-group trial, conducted as a single center study. Patients were randomly assigned (balanced 1:1) to either MASS or OS. A third- 


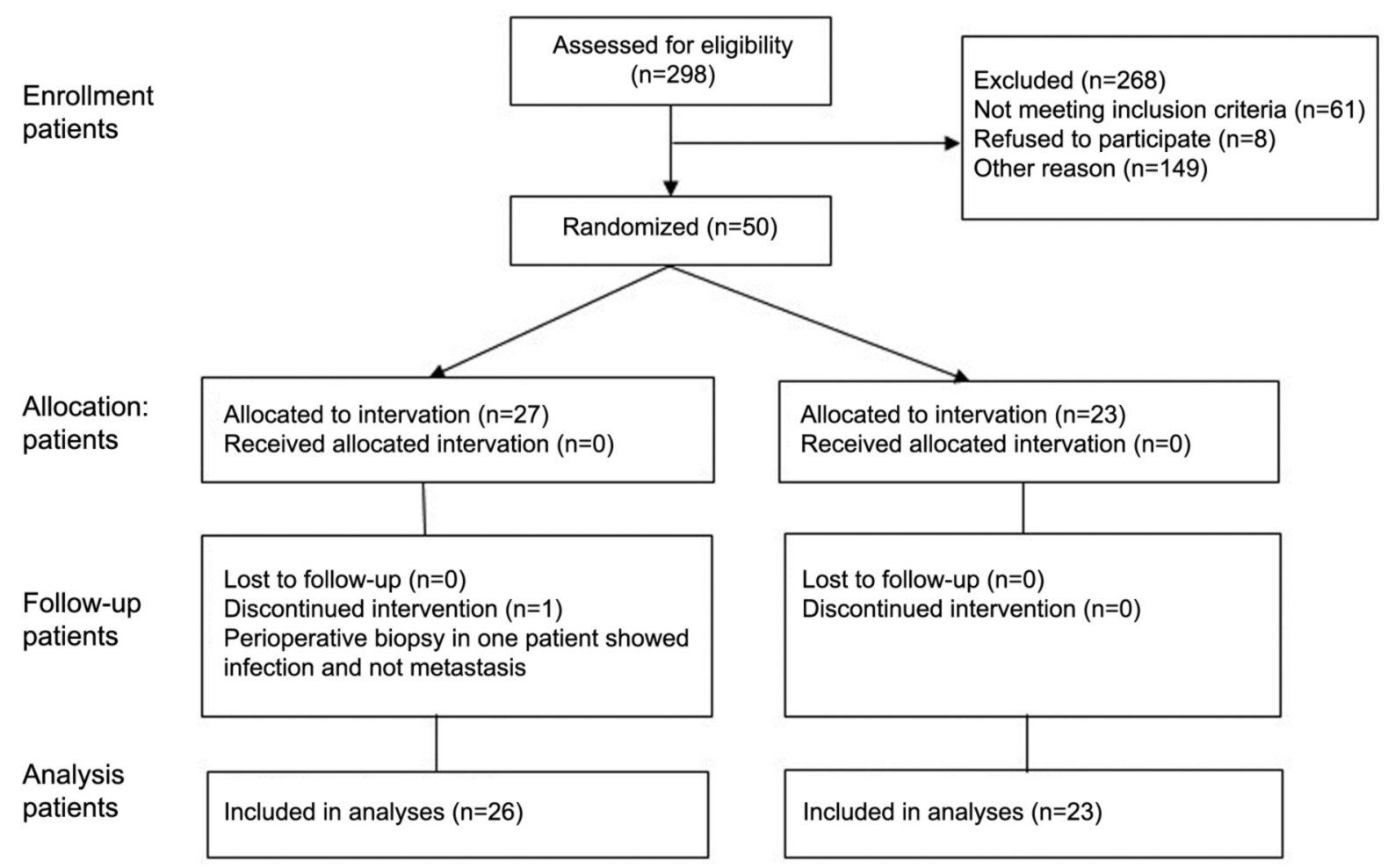

Figure 1. Flow of patients in the study.

party computer-generated list of random numbers and a fixed block size of 20 made the allocation sequencing. Informed consent was obtained from all individual patients. The allocation concealment was secured by using sealed, numbered envelopes. The envelopes were opened immediately after agreement with the patient. The patient, surgeon and staff members were non-blinded.

From previous studies including patients with spinal metastases from a wider range of primary cancers and based on patient files, it was calculated that the mean blood loss during open surgery was $1,500 \mathrm{ml}$ (standard deviation $13.5 \mathrm{ml})(9,10)$. A clinically relevant reduction in blood loss was considered to be $400 \mathrm{ml}$, corresponding to one unit of packed red blood cells. With a significance level of $5 \%$ and a power of $80 \%$ it was estimated that a total of 62 included patients would be necessary. The trial was closed when the prescheduled date of closure was reached. By then, a total of 2.5 blocks and 50 patients were included. The study was approved by the Danish National committee on Biomedical Research Ethics (Identifier: H-2-2011-050), and the study was preregistered at ClinicalTrials.gov (Identifier: NCT01865942). All procedures were in accordance with the ethical standards of the institutional and/or national research committee and with the 1964 Helsinki declaration and its later amendments or comparable ethical standards. All participants provided informed consent.

Treatment procedure. All patients were operated with posterior pedicle screw instrumentation two levels above and two levels below the metastatic level. In the MASS-group, decompression was performed through a localized incision at the metastatic level. In the OS-group decompression was performed through a conventional laminectomy. The decompression was done only posteriorly with decompression of the nerve roods. Any visible tumor mass was removed. Tumor mass was also removed if it compressed the neurologic structures. However, the goal was not to remove as much tumor mass as possible. During the operation, the surgeons took biopsies from the vertible body and the dissected tumor. According to standard procedure, biopsies were sent for analysis for infection and pathology.

Clinical outcomes. The primary outcome was perioperative blood loss and secondary outcomes were operation time and complications (infections and instrumentation failures). Perioperative blood loss was measured as the volume in suction containers and as the weight of surgical sponges $(1 \mathrm{~g}=1 \mathrm{ml})$. Operation time was measured from first incision to last suture. Infections and instrumentation failures were included as complications if revision surgery was needed. We also registered if there was delayed wound healing or mild infection that lead to postponed radiotherapy or chemotherapy treatment.

Statistical analyses. The MASS and OS groups were compared using independent $t$-test for continuous variables with a normal distribution and homogeneity of variances and Mann-Whitney test for continuous variables with a skewed distribution. The possible difference in survival between the two groups was estimated with Kaplan-Meier survival curves and multivariate Cox regression analysis including $95 \%$ confidence intervals $(95 \% \mathrm{CI})$. A $p$-value $<0.05$ was considered statistically significant. Analyses were conducted using Stata 14 (StataCorp, College Station). 
Table I. Baseline characteristics in the minimal access spine surgery (MASS) and the open surgery groups (OS).

\begin{tabular}{|c|c|c|c|}
\hline \multirow[t]{2}{*}{ Characteristics } & \multirow{2}{*}{$\frac{\text { MASS Group, } \mathrm{n}=23}{\text { Median (range) or Mean } \pm \text { SD or } \% 1}$} & \multirow{2}{*}{$\frac{\text { OS group, } \mathrm{n}=26}{\text { Median (range) or Mean } \pm \text { SD or } \% 1}$} & \multirow[t]{2}{*}{$p$-Value ${ }^{2}$} \\
\hline & & & \\
\hline Age (years) & $65.9($ range $=49-85)$ & $67.6($ range $=42-88)$ & 0.400 \\
\hline Gender & Male $38 \%$ & Male $43 \%$ & 0.724 \\
\hline Primary site of cancer & & & 0.384 \\
\hline Lung & 3 & 6 & \\
\hline Breast & 9 & 7 & \\
\hline Prostate & 4 & 1 & \\
\hline Unidentified & 4 & 1 & \\
\hline Renal & 2 & 3 & \\
\hline Pancreatic & 1 & 0 & \\
\hline Melanoma & 0 & 1 & \\
\hline Thyroid & 0 & 1 & \\
\hline Lymphoma & 3 & 0 & \\
\hline Other & 0 & 3 & \\
\hline 2017 Revised Tokuhashi score (28) & $8.0($ range $=4-12)$ & $7.6($ range $=3-12)$ & 0.650 \\
\hline $0-5$ & 4 & 4 & \\
\hline $6-9$ & 10 & 11 & \\
\hline $10-12$ & 8 & 8 & \\
\hline \multicolumn{4}{|l|}{$\begin{array}{l}\text { Spinal level of the metastasis } \\
\text { decompressed during surgery }\end{array}$} \\
\hline TH 5-8 & 6 & 7 & 0.236 \\
\hline TH 9-12 & 11 & 10 & \\
\hline L 1-3 & 9 & 6 & \\
\hline
\end{tabular}

${ }^{1}$ Values are percentages for categorical variables, means (SD) for continuous variables with a normal distribution, or medians (range) for continuous variables with a skewed distribution; ${ }^{2} p$-value comparing the MASS and the OS group, assessed using independent $t$-test for continuous variables with a normal distribution and homogeneity of variances, Mann-Whitney test for continuous variables with a skewed distribution and chi-square tests for categorical variables.

\section{Results}

A total of 53 patients were offered to be part of the study (Figure 1) and 50 agreed to participate. A total of 27 were randomized in the MASS group and 23 in the OS group. One patient in the MASS group was excluded because the biopsies showed that the patient suffered from a chronic infection instead of cancer. All included patients were operated, and none were lost to follow-up.

There was no significant difference between the MASSand the OS-group regarding sex, age, 2005 Revised Tokuhashi Score or primary tumor diagnosis (Table I).

The MASS technique resulted in significantly lower blood loss and a significantly longer operation time when compared to the OS technique (Table II). The median blood loss in the MASS group was 0.1751 (range $=0.03-0.801$ ) versus 0.500 (range $=0.100-2.001$ ) in the OS group. The median operation time in the MASS group was $142 \mathrm{~min}$ (range $=72-203 \mathrm{~min}$ ) versus $103 \mathrm{~min}$ (range=59-435 $\mathrm{min}$ ) in the OS group. The number of reoperations were the same, with two in each group. In the OS group, one reoperation was necessary because of instrumentation failure and one patient was re-operated because of a wrong level of instrumentation and decompression during the first operation. In the MASS-group, one patient was re-operated because of deep infection and one for instrumentation failure. Except from the patient treated with revision surgery, no other patient suffered from delayed wound healing or mild infection that led to postponement of radiotherapy or chemotherapy treatment.

The pre-and postoperative hemoglobin was not different between the MASS and the OS group. The survival time was longest in the MASS group 637.9 (range=39-1497 months) $v s$. 461.4 (range=29-1365 months) in the OS group, but the difference was not significantly different $(p=0.133)$. The difference in survival between the MASS and the OS group was further examined via Kaplan-Meier survival curves (Figure 2).

\section{Discussion}

In this randomized clinical trial based on 49 patients with MSCC, we found that by using the MASS technique, blood loss was significantly reduced and the operation time was significantly increased compared to open surgery. There was a tendency for a longer survival in the MASS group, when compared to the OS group, but this was not statistically significant. 
Table II. Peri- and post-operative characteristics of the patients in the minimal access spine surgery (MASS) and the open surgery (OS) group.

\begin{tabular}{|c|c|c|c|}
\hline \multirow[t]{2}{*}{ Characteristics } & \multirow{2}{*}{$\frac{\text { MASS Group, } \mathrm{n}=23}{\text { Median (range) }^{1}}$} & \multirow{2}{*}{$\frac{\text { OS group, } \mathrm{n}=26}{{\text { Median }(\text { range })^{1}}^{1}}$} & \multirow[t]{2}{*}{$p$-Value ${ }^{2}$} \\
\hline & & & \\
\hline Perioperative blood loss, (1) & $0.175($ range $=0.030-0.800)$ & $0.500($ range $=0.100-2.000)$ & 0.002 \\
\hline Operation time, $(\mathrm{min})$ & $142($ range $=72-203)$ & $103($ range $=59-435)$ & 0.001 \\
\hline Number of complications & 2 & 2 & 0.899 \\
\hline Preoperative hemoglobin $(\mathrm{mmol} / \mathrm{l}) \pm \mathrm{SD}$ & $7.9($ range $=5.8-10.4)$ & $8.0($ range $=5.7-9.5)$ & 0.944 \\
\hline Postoperative hemoglobin $(\mathrm{mmol} / \mathrm{l}) \pm \mathrm{SD}$ & $7.1($ range $=5-9.3)$ & $6.7($ range $=4.6-8.2)$ & 0.167 \\
\hline Survival in days & $637.9($ range $=39-1,497)$ & $461.4($ range $=29-1,365)$ & 0.133 \\
\hline
\end{tabular}

${ }^{1}$ Values are percentages for categorical variables, means (SD) for continuous variables with a normal distribution, or medians (range) for continuous variables with a skewed distribution; ${ }^{2} p$-value comparing the MASS and the OS group, assessed using independent $t$-test for continuous variables with a normal distribution and homogeneity of variances, Mann-Whitney test for continuous variables with a skewed distribution and chi-square tests for categorical variables.

Surgical treatment of MSCC patients is primarily a palliative procedure that is offered with the intention of preserving neurologic function and to relieve pain. The decision to offer surgical treatment is complicated by the fact that a large proportion of MSCC patients need oncologic treatment after surgery (11). Common treatments offered are chemotherapy and radiation therapy with the risk of complications like infection and revision surgery. These factors may delay or deprive the MSCC patients of the possibility of adjuvant treatment (12-14). Previous studies have shown that wound complications are seen in 10 percent of all MSCC patients receiving surgical treatment, and that surgery often results in considerable perioperative bleeding (13-15).

One of the major strengths of this study is that it is a one center randomized controlled trial and all patients were operated by a small team of skilled surgeons. There were no dropouts from the study. It can also be considered as a major strength that the treatment facility serves an entire region consisting of 2.5 million people, making the data representative of the country, with a high degree of external validity.

One important limitation of this study was its small sample size. It could be suggested that the inclusion of a larger number of patients into the study would have increased the statistical power to detect a significant difference in the number of reoperations due to wound complications and in survival time between the two groups.

Previous studies have reported a complication rate of 5$10 \%$ in patients operated with MASS technique versus a complication rate of $7 \%$ in the OS groups $(13,14,16-18)$. Wound complications that led to revision surgery were registered for all patients. One patient had wound complication, which led to revision surgery. We collected information on prolonged wound healing and postponement of radiotherapy due to prolonged wound healing for all patients. Compared to other previous studies our wound complication rate was low.

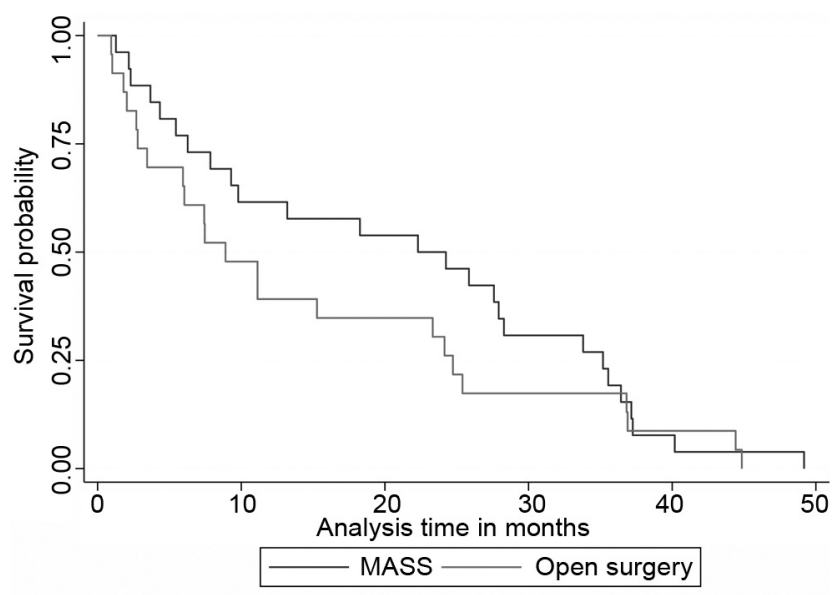

Figure 2. Kaplan-Meier survival estimates for patients treated with minimally access spine surgery (MASS) or open Surgery.

Two recent systematic reviews have compared minimal access surgery with open surgery in patients suffering from $\operatorname{MSCC}(7,8)$. Lu et al. included six cohort studies (three prospective and three retrospective) representing a total of 252 patients (19-24). Lu et al. concluded that are many surgical advantages to the use of MASS compared with OS, such as reduced blood loss and fewer complications, however, future larger cohort studies and future randomized trials are needed to validate the findings. In the review by Pennington $e t a l$., the authors analyzed the same six studies along with two further retrospective cohort studies, thereby including further 21 patients, and concluded that the level of the available evidence is low $(25,26)$. Both studies emphasize a well-designed study by Hansen-Algenstaedt $e t$ al. (19). In this study, the authors compared 30 patients treated with OS with 30 patients treated with MASS. Hansen-Algenstaedt et al. concluded that MASS can be a 
good alternative to conventional OS (19). They found, in accordance with our study, less bleeding in patients treated with MASS. In the Hansen-Algenstaedt study, the operation time was shorter, which is not in line with our findings. The differences may partly be attributable to different MASS procedures at the different hospitals.

In a cohort study by Hikata et al., the authors compared 25 patients operated with MASS with 25 patients operated with OS. The results showed a significantly lower blood loss (340 versus $714 \mathrm{ml}$ ) and complication rate (3 versus 11 patients) in the MASS group (27). We found equal complication rates with 2 complications in each group, which is not in line with the study by $\mathrm{T}$ et al. The difference in the complication rates in the study by Hikata et al. was not discussed but is a very important aspect of the comparison and needs to be addressed and described further in future studies, if a difference is found (27).

In the study by Hansen-Algenstaedt et al. the authors concluded that MASS could be the optimal surgical option for patients with the most advanced metastatic disease. MSCC patients are vulnerable and complications from surgery may shorten survival time. The survival time among operated MSCC patients may further be shortened by the delay of adjuvant radiation therapy and chemotherapy. For this reason, we analyzed the difference in survival between the MASS and the OS group. Patients operated with the MASS technique had longer survival times (638 months versus 461 months), but this was not a statistically significant difference. More studies, preferably randomized clinical trials, need to be conducted to examine the difference in survival time in a larger MSCC population.

Based on this randomized clinical trial, we conclude that the MASS technique in MSCC patients is associated with less blood loss, but a longer operation time when compared to the OS technique. In our study, the complicationrate was equal in the two groups. This knowledge supports what has previously been found in observational studies, however, more or larger RCT's may reveal whether the MASS technique is associated with a longer survival time than the OS technique.

\section{Conflicts of Interest}

All Authors declare no conflict of interest in relation to this study.

\section{Authors' Contributions}

Søren Schmidt Morgen, MD, Ph.D.: Conceptualization, data curation, formal analysis, writing - original draft, writing - review \& editing; Lars Valentin Hansen, MD: Conceptualization, writing review \& editing; Ture Karbo, MD: Data curation, writing - review \& editing; Robert Svardal-Stelmer, MD: Data curation, writing review \& editing; Martin Gehrchen, MD, Ph.D.: Conceptualization, writing - review \& editing; Benny Dahl, MD, Ph.D., DMSci: Conceptualization, writing - review \& editing.

\section{Acknowledgements}

Benny Dahl has received grants from The Strategic Research Council of Denmark, during the conduct of the study; and grants from Medtronic, grants from $\mathrm{K} 2 \mathrm{M}$, personal fees from $\mathrm{K} 2 \mathrm{M}$, outside the submitted work.

\section{References}

1 Engholm G, Gislum M, Bray F and Hakulinen T: Trends in the survival of patients diagnosed with cancer in the Nordic countries 1964-2003 followed up to the end of 2006. Material and methods. Acta Oncol 49: 545-560, 2010. PMID: 20491523. DOI: $10.3109 / 02841861003739322$

2 Morgen SS, Lund-Andersen C, Larsen CF, Engelholm SA and Dahl B: Prognosis in patients with symptomatic metastatic spinal cord compression: Survival in different cancer diagnosis in a cohort of 2321 patients. Spine 38: 2013. PMID: 23574811. DOI: 10.1097/BRS.0b013e318294835b

3 Patchell R, Tibbs PA, Regine WF, Payne R, Saris S, Kryscio RJ, Mohiuddin M and Young B: Direct decompressive surgical resection in the treatment of spinal cord compression caused by metastatic cancer: a randomised trial. Lancet 366: 643-648, 2005. PMID: 16112300. DOI: 10.1016/S0140-6736(05)66954-1

4 Sciubba DM, Rory JP, Mark BD, Charles GF, Michael GF, Stephen LO, Laurence DR and Ziya LG: Diagnosis and management of metastatic spine disease. J Neurosurg Spine 13: 94-108, 2010. PMID: 20594024. DOI: 10.3171/2010.3. SPINE09202

5 Choi, David, Crockard A, Bunger C, Harms J, Kawahara N, Mazel C, Melcher R and Tomita K: Review of metastatic spine tumour classification and indications for surgery: the consensus statement of the Global Spine Tumour Study Group. Eur Spine J 19: 215-222, 2010. PMID: 20039084. DOI: 10.1007/s00586009-1252-x

6 Morgen SS, Engelholm SA, Larsen CF, Sogaard R and Dahl B: Health-related quality of life in patients with metastatic spinal cord compression. Orthop Surg 8: 309, 2016. PMID: 27627713. DOI: $10.1111 /$ os.12253

7 Pennington, Zach, Karim AA, Camilo AM, Jeffrey E, Ilya L and Sciubba DM: Minimally invasive versus conventional spine surgery for vertebral metastases: a systematic review of the evidence. Ann Transl Med 6: 103, 2018. PMID: 29707552. DOI: 10.21037/atm.2018.01.28

8 Lu VM, Alvi MA, Goyal A, Kerezoudis P and Bydon M: The potential of minimally invasive surgery to treat metastatic spinal disease versus open surgery: a systematic review and metaanalysis. World Neurosurg 112: e859-e868, 2018. PMID: 29408300. DOI: 10.1016/j.wneu.2018.01.176

9 Clausen C, Lönn L, Morgen SS, Nielsen MB, Frevert SC, Johansson PI and Dahl B: Perioperative blood transfusion does not decrease survival after surgical treatment of spinal metastases. Eur Spine J, 2014. PMID: 24866254. DOI: 10.1007/s00586-014-3330-y

10 Clausen C, Dahl B, Frevert SC, Hansen LV, Nielsen MB and Lars Lönn L: Preoperative embolization in surgical treatment of spinal metastases: Single-blind, randomized controlled clinical trial of efficacy in decreasing intraoperative blood loss. J Vasc Interv Radiol 26: 402-412, 2015. PMID: 25636672. DOI: 10.1016/j.jvir.2014.11.014 
11 Stergios B, Cooke D, Hayward C, Foivos S. K anellos, Alexandros KT, Aikaterini AC, Nikolaos ZK and Karathanasi A: Review: Metastatic spinal cord compression: unraveling the diagnostic and therapeutic challenges. Anticancer Res 38: 49874997, 2018. PMID: 30194142. DOI: 10.21873/anticanres.12817

12 Uei, Hiroshi, Tokuhashi Y, Maseda M, Nakahashi M, Sawada H, Nakayama E and Soma H: Clinical results of multidisciplinary therapy including palliative posterior spinal stabilization surgery and postoperative adjuvant therapy for metastatic spinal tumor. J Orthopaed Surg Res 13: 2018. PMID: 29402333. DOI: 10.1186/s13018-018-0735-Z

13 Hannah CM, Ahmed AK, Abu-Bonsrah N, Ramos RG, Sankey EW, Pennington $\mathrm{Z}$ and Bydon A: Risk factors for wound-related reoperations in patients with metastatic spine tumor. J Neurosurg Spine 28: 1-6, 2018. PMID: 29547061. DOI: 10.3171/2017.10.SPINE1765

14 Pereira NRP, Paul T, Groot OQ, Hornicek FJ, Dijk CN, Brammer JAM and Schwab JH: Complications and reoperations after surgery for 647 patients with spine metastatic disease. Spine J 19: 144-156, 2019. PMID: 29864546. DOI: 10.1016/ j.spinee.2018.05.037

15 Chen Y, Tai BC, Nayak D, Kumar N, Chua KH, Lim JW, Goy RWL and Wong HK: Blood loss in spinal tumour surgery and surgery for metastatic spinal disease: a meta-analysis. Bone Joint J 95: 683-688, 2013. PMID: 23632682. DOI: 10.1302/0301620X.95B5

16 Liu YH, Yong CH, Xiong GY, Deng XL, Feng W, Li Y, Hao Z, Jiang TF and Kun $\mathrm{CH}$ : Prognostic factors of ambulatory status for patients with metastatic spinal cord compression: a systematic review and meta-analysis. World Neurosurg 116: e278-e290, 2018. PMID: 29733989. DOI: 10.1016/j.wneu.2018.04.188

17 Elsamadicy AA, Owoicho A, David TL, Amanda RS, Sohrab V, Eric WS, Joseph C, Carlos AB and Isaac OK: Thirty-day complication and readmission rates associated with resection of metastatic spinal tumors: a single institutional experience. J Spine Surg 4: 304-310, 2018. PMID: 30069522. DOI: 10.21037/jss.2018.05.14

18 Phan K, Zoe BC, Khushdeep SV, Awais KH, Mauricio CL, Jun SK, John DC and Samuel KC: Age stratification of 30-day postoperative outcomes following excisional laminectomy for extradural cervical and thoracic tumors. Global Spine J 8: 490497, 2018. PMID: 30258755. DOI: 10.1177/2192568217745824

19 Hansen-Algenstaedt N, Kwan MK, Algenstaedt P, Chiu CK, Viezens L, Chan TS, Lee CK, Wellbrock J, Chan CYW and Schaefer C: Comparison between minimally invasive surgery and conventional open surgery for patients with spinal metastasis. Spine (Phila Pa 1976) 42: 789-797, 2017. PMID: 27584676. DOI: $10.1097 /$ BRS.0000000000001893

20 Hikata T, Isogai N, Shiono Y, Funao H, Okada E, Fujita N and Iwanami A: A retrospective cohort study comparing the safety and efficacy of minimally invasive versus open surgical techniques in the treatment of spinal metastases. Clin Spine Surg 30: 1082-1087, 2017. PMID: 27841799. DOI: 10.1097/BSD.0000000000000460
21 Huang TJ, Hsu WWR, Li YY and Cheng CC: Minimal access spinal surgery (MASS) in treating thoracic spine metastasis. Spine (Phila Pa 1976) 31: 1860-1863, 2006. PMID: 16845365. DOI: $10.1097 / 01 . b r s .0000225995 .56028 .46$

22 Kumar N, Rishi M, Karthikeyan M, Aye SZ, Pang HW, Milindu CM, Gabriel KPL, Joseph T and Hee-Kit KW: Metastatic spine tumor surgery. Clin Spine Surg 30: E1015-E1021, 2017. PMID: 28437329. DOI: $10.1097 /$ BSD .0000000000000528

23 Lau D and Chou D: Approach to the open approach. J Neurosurg Spine 23: 217-227, 2015. PMID: 25932599. DOI: 10.3171/ 2014.12.SPINE14543

24 Miscusi M, Polli FM, Forcato S, Ricciardi L, Frati A, Cimatti M, Martino LD, Ramieri A and Antonino R: Comparison of minimally invasive surgery with standard open surgery for vertebral thoracic metastases causing acute myelopathy in patients with short- or mid-term life expectancy: surgical technique and early clinical results. J Neurosurg Spine 22: 518-525, 2015. PMID: 25723122. DOI: 10.3171/2014.10.SPINE131201

25 Fang T, Dong J, Zhou X, McGuire RA and Li X: Comparison of mini-open anterior corpectomy and posterior total en bloc spondylectomy for solitary metastases of the thoracolumbar spine. J Neurosurg Spine 17: 271-279, 2012. PMID: 22881038. DOI: $10.3171 / 2012.7 . S P I N E 111086$

26 Stoker GE, Buchowski JM, Kelly MP, Meyers BF and Patterson GA: Video-assisted thoracoscopic surgery with posterior spinal reconstruction for the resection of upper lobe lung tumors involving the spine. Spine J 13: 68-76, 2013. PMID: 23295033. DOI: $10.1016 /$ j.spinee.2012.11.026

27 Hikata T, Isogai N, Shiono Y, Funao H, Okada E, Fujita N and Iwanami A: A retrospective cohort study comparing the safety and efficacy of minimally invasive versus open surgical techniques in the treatment of spinal metastases. Clin Spine Surg 30: E1082-E1087, 2017. PMID: 27841799. DOI: 10.1097/ BSD.0000000000000460

28 Morgen SS, Fruergaard S, Gehrchen M, Bjørck S, Engelholm SA and Dahl B: A revision of the Tokuhashi revised score improves the prognostic ability in patients with metastatic spinal cord compression. J Cancer Res Clin Oncol 144: 33-38, 2018. PMID: 28986702. DOI: 10.1007/s00432-017-2519-y

Received June 26, 2020

Revised July 15, 2020

Accepted July 23, 2020 